\title{
KAISER-HAMMING PENCERESİ VE YİNELEMESİZ SAYISAL SÜZGEÇ TASARIMI İÇİN PERFORMANS ANALIZi̇
}

\author{
Kemal AVCI \\ Abant İzzet Baysal Üniversitesi, Elektrik ve Elektronik Mühendisliği Bölümü, Gölköy Kampüsü, Bolu \\ kavci1980@gmail.com
}

(Geliş/Received: 02.06.2013; Kabul/Accepted: 04.09.2014)

ÖZET

$\mathrm{Bu}$ makalede, elektronik mühendisliğinin birçok uygulamasında kullanım alanına sahip yinelemesiz sayısal süzgeçlerin tasarımı için yeni bir pencere fonksiyonu önerilmektedir. Adından da anlaşılacağı üzere bu pencere, literatürde Kaiser ve Hamming olarak bilinen iki farklı pencerenin birleştirilmesiyle elde edilmiştir. Önerilen pencere, ilk olarak, pencere spektral parametreleri olarak bilinen tepecik oranı ve analob genişliği cinsinden analiz edilmektedir. Ayrıca, önerilen pencerenin; Kaiser ve Hamming pencereleriyle pencere spektral karşılaştırmaları yapılmaktadır. Pencere benzeşim sonuçları, önerilen pencerenin; sabit pencere uzunluğu ve analob genişliğinde daha iyi tepecik oranı sağlayabileceğini göstermektedir. İkinci olarak, önerilen pencerenin yinelemesiz sayısal süzgeç tasarımındaki analizi; süzgeç spektral parametreleri olarak bilinen, minimum durdurma-bandı zayıflatması ve geçiş bandı genişliği cinsinden yapılmakta ve ayrıca Kaiser, Cosh, Exponential ve Hamming pencereleriyle karşılaştırmaları verilmektedir. Süzgeç karşılaştırma sonuçları, önerilen pencere ile tasarlanan alçak geçiren süzgeçlerin; sabit süzgeç uzunluğu ve geçiş bandı genişliğinde, diğerlerinden daha iyi minimum durdurma-bandı zayıflatması sağlayabileceğini göstermektedir. Yani, önerilen pencere ile daha iyi bir süzgeç performansı sergilenebileceği sonucuna varılmaktadır. Bu sonuç, ses işaretindeki bir gürültünün, önerilen pencereyle daha iyi süzgeçlendiğinin gösterilmesi ile ayrıca desteklenmektedir.

Anahtar kelimeler: Yinelemesiz sayısal süzgeçler, pencere fonksiyonları, Kaiser-Hamming penceresi, Kaiser penceresi, Hamming penceresi

\section{KAISER-HAMMING WINDOW AND ITS PERFORMANCE ANALYSIS FOR NONRECURSIVE DIGITAL FILTER DESIGN}

\begin{abstract}
In this paper, a new window function is proposed for the design of nonrecursive digital filters which have area of usage in many applications of electronics engineering. As the name implies, this window is obtained by the combination of two different windows in literature, known as Kaiser and Hamming. The proposed window is first analyzed in terms of ripple ratio and mainlobe width, which are known as window spectral parameters. Moreover, window spectral comparisons of the proposed window with Kaiser and Hamming windows are performed. The window simulation results show that the proposed window can provide better ripple ratio for fixed window length and mainlobe width. Secondly, the analysis of the proposed window in nonrecursive digital filter design is performed in terms of minimum stopband attenuation and transition width, which are known as filter spectral parameters, and also its comparisons with Kaiser, Cosh, Exponential, and Hamming windows are given. Filter comparison results show that the filters designed by the proposed window can provide better minimum stopband attenuation than the ones designed by the others for fixed filter length and transition band width. That is, it is concluded that with the proposed window a better filter performance can be exhibited. This conclusion is supported by demonstrating better filtering of a noise in an audio signal with the proposed window.
\end{abstract}

Keywords: Nonrecursive digital filters, window functions, Kaiser-Hamming window, Kaiser window, Hamming window 


\section{GÍRIŞ (INTRODUCTION)}

Elektronik mühendisliğinin birçok uygulamasında kullanılan süzgeçler, fiziksel yapılarına göre analog ve sayısal olarak sınıflandırılırlar. Analog süzgeçlerin gerçekleştirilmesinde; direnç, kondansatör, işlevsel yükselteç veya işlevsel geçiş-iletkenliği yükseltici gibi pasif ve aktif analog elektronik devre elemanları kullanılmaktadır. Sayısal işaret işleme uygulamalarının en önemli ve en çok kullanılan elemanlarından olan sayısal süzgeçler ise hem yazılımsal hem de donanımsal olarak gerçekleştirilirler. Kişisel bilgisayarlarda veya gömülü sistemlerde oluşturulan sayısal süzgeçlerin donanımsal gerçekleştirmelerinde; toplayıcı, çarpıcı ve geciktirici gibi sayısal elektronik devre elemanları kullanılmaktadır.

Sayısal süzgeçler, amaca göre yinelemesiz veya yinelemeli olarak gerçekleştirilirler. Yinelemeli süzgeçler, daha az süzgeç uzunluğuyla (toplam süzgeç katsayı sayısı) tasarlanabilir; bu da, eşdeğer devrenin daha az elemanlı olması anlamına gelir. Yinelemesiz süzgeçler ise daima kararlı ve tam doğrusal faz özellikli olarak kolayca tasarlanabilmeleri gibi önemli avantajlara sahiptir [1].

Yinelemesiz süzgeçler; Fourier serisi, optimizasyon, frekans örnekleme ve nümerik yöntemler gibi değişik yollarla tasarlanabilirler. Bunlar içinde en basit ve ayrıca en çok kullanılan yöntem, pencere fonksiyonu (veya kısaca pencere) kullanarak yapılan Fourier seri metodudur. $\mathrm{Bu}$ metotta pencerelerin kullanılmasinın amacı, Fourier serinin direkt olarak kesilmesiyle süzgeç genliğinde oluşan istenmeyen salınımların azaltılmasıdır. Bu metodun en önemli dezavantajı, optimum sonuçlar vermemesidir. $\mathrm{Bu}$ yüzden literatürde birçok pencere önerilmiş ve hala bu konuda çalışmalar devam etmektedir [2-10]. Pencereler, bağımsız parametre sayılarına göre sabit ve ayarlanabilir olarak sinıflandırılırlar [11]. Rectangular, Von-Hann, Hamming ve Blackman pencereleri sabit pencereler olup, bu tür pencereler sadece bir bağımsız parametreye sahiptirler. İki veya daha fazla değişkene sahip pencereler, ayarlanabilir olarak adlandırılırlar. Kaiser penceresi [2, 12]; sahip olduğu iki bağımsız parametrenin verdiği esneklik ve kapalı formda türetilmiş süzgeç tasarım denklemleriyle, yinelemesiz süzgeç tasarımında en çok bilinen ve kullanılan penceredir. Kaiser penceresi; biyomedikal ve haberleşme gibi alanlarda değişik pencere ve süzgeç uygulamalarında kullanılmaktadır [13-18]. Bir pencerenin kalitesinin analizinde, pencere spektral parametreleri olarak bilinen tepecik oranı ve analob genişliği parametreleri kullanılmaktadır [19]. $\mathrm{Bu}$ yüzden, pencere spektral analizi, pencerenin uygulamadaki performansı hakkında bize ön bilgi vermektedir.

$\mathrm{Bu}$ çalışmada, Kaiser penceresine göre daha iyi süzgeçleme yapmak için Kaiser ve Hamming pencereleri birleştirilerek yeni bir pencere önerilmiştir. Sonraki bölümde, pencereler ve bunların süzgeçlemede kullanımı hakkında temel bilgi ve kavramlar anlatılacak ve önerilen pencere bu kısımda tanıtılacaktır. Üçüncü bölümde ise önerilen pencerenin, pencere ve süzgeç spektral analizleri yapılacak; Kaiser, Cosh, Exponential ve Hamming pencereleriyle karşılaştırılmaları verilecektir. Aynı bölümde, tasarlanan süzgeçlerin performans1, gürültülü bir ses işareti üzerinde incelenecektir.

\section{MATERYAL VE YÖNTEM (MATERIAL AND METHOD)}

Bu bölümde; çalışmada kullanılan materyal, konuyla ilgili kavramlar ve fonksiyonlar ile matematiksel yöntem anlatılmıştır.

\subsection{Materyal (Material)}

$\mathrm{Bu}$ çalışma ile ilgili tüm işlemler, Mathworks firmasina ait Matlab R2009b yazılımı vasitasıyla gerçekleştirilmiştir. Simülasyon sonuçları; 2,30 GHz işlemci hızına sahip bir PC'de Sptool arayüzü ve bu çalışmanın yazarı tarafindan yazılan m-file programları ile elde edilmiştir.

\subsection{Pencerenin Tanımı (Definition of Window)}

$N$ uzunluğuna sahip bir pencere, $w(n T),|n| \leq(N-1) / 2$ aralığında sıfırdan farklı ve geri kalan aralık için ise sıfir olan zaman alanlı bir fonksiyondur [1]. Şekil 1a'da, $\mathrm{N}=31$ için çizilmiş, tipik bir ayrık zamanlı pencerenin genlik karakteristiği görülmektedir.

Pencerelerin performans analizi sadece frekans alanında yapılmaktadır. Tek sayı uzunluklu ve simetrik bir pencerenin frekans spektrumu, Denklem (1)'den bulunabilir.

$W\left(e^{j w T}\right)=|A(w)| e^{j \theta(w)}=w(0)+2 \sum_{n=1}^{(N-1) / 2} w(n T) \cos w n T$

Burada, $A(w)$ ve $\theta(w)$, sirasıyla pencerenin genlik ve faz spektrumunu; $T$ ise örnekleme periyodunu göstermektedir. Bölüm 2.7 ve 3.2.3 hariç, bu makalenin geri kalan kısmında yapılan tüm hesaplamalarda, basitlik açısından örnekleme periyodu bir saniye olarak kullanılmıştır (Yani, T = 1). Şekil 1b'de tipik bir pencerenin dB ölçeğinde normalize genlik spektrumu görülmekte olup, Denklem (2) ile elde edilebilir.

$$
\left|W_{N}\left(e^{j w T}\right)\right|=20 \log _{10}\left(|A(w)| /|A(w)|_{\max }\right)
$$




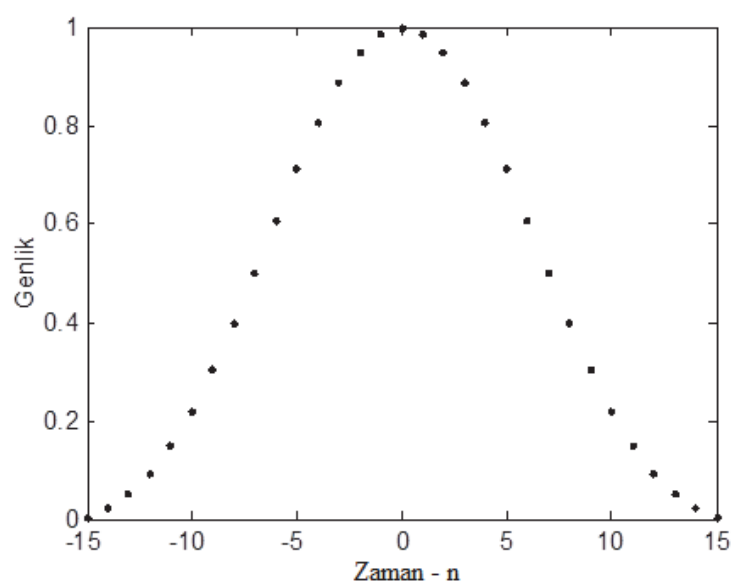

(a)

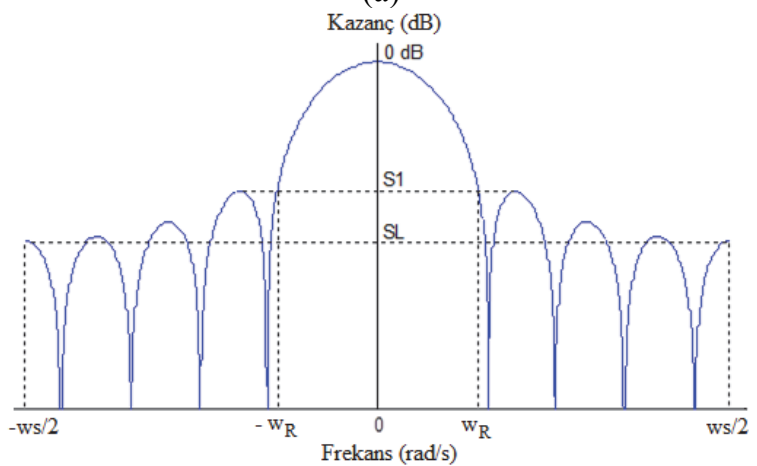

(b)

Şekil 1. (a) Tipik bir pencerenin normalize genlik karakteristiği $(\mathrm{N}=31)$ ve (b) Tipik bir pencerenin normalize genlik spektrumu ((a) Normalized amplitude characteristic of a typical window $(\mathrm{N}=31)$ and $(b)$ Normalized amplitude spectrum of a typical window)

Pencerelerin spektral performansını değerlendirmek için kullanılan analob genişliği $\left(\mathrm{w}_{\mathrm{M}}=2 \mathrm{w}_{\mathrm{R}}\right)$ ve tepecik oranı $\left(\mathrm{R}=\mathrm{S}_{1}\right)$ parametreleri, Şekil 1b'de gösterilmiştir. İşaret işleme uygulamalarında, bir pencerenin, daha küçük tepecik oranı ve daha dar analob genişliğine sahip olması istenmektedir. Fakat bu istek bir çelişkidir; yani, bir parametre iyileștirilirken diğeri daha kötü bir değere gelmektedir.

\subsection{Kaiser Penceresi (Kaiser Window)}

Ayrık zamanda, Kaiser penceresi Denklem (3)'te belirtildiği gibi tanımlanmıştır $[2,12]$.

$w_{k}(n)=\frac{I_{0}\left(\alpha_{k} \sqrt{1-\left(\frac{2 n}{N-1}\right)^{2}}\right)}{I_{0}\left(\alpha_{k}\right)}|\mathrm{n}| \leq(\mathrm{N}-1) / 2$ için

Burada $N$ pencere uzunluğunu, $\alpha_{k}$ ayarlanabilir bağımsız parametreyi ve $I_{0}(x)$ ise sıfir dereceli birinci tür geliştirilmiş Bessel fonksiyonunu göstermektedir. $I_{0}(x)$, Denklem (4) ile ifade edilen güç serisi açılımıyla tanımlanmaktadır.

$$
I_{0}(x)=1+\sum_{k=1}^{\infty}\left[\frac{1}{k !}\left(\frac{x}{2}\right)^{k}\right]^{2}
$$

\subsection{Hamming Penceresi (Hamming Window)}

İşaret işleme uygulamalarında sıklıkla kullanılan Hamming penceresi, bağımsız değişken olarak sadece pencere uzunluğuna sahip olup, Denklem (5) ile tanımlanmaktadır [1].

$w_{h}(n)=0,54-0,46 \cos \frac{2 \pi n}{N-1} \mathrm{n}=0,1, \ldots, \mathrm{N}-1$

\section{5. Önerilen Pencere: Kaiser-Hamming Penceresi (Proposed Window: Kaiser-Hamming Window)}

Kaiser penceresinden daha iyi bir performans sağlayabilmek için, değişik pencere birleşimleri denenmiş ve Kaiser ile Hamming pencerelerinin oluşturduğu pencere kombinasyonun üçüncü bölümde anlatıldığı üzere amaca uygun tatmin edici sonuçlar verdiği gözlemlenmiştir. Bu çalışmada, önerilen pencere, Kaiser-Hamming olarak adlandırılmış ve Denklem (6) ile tanımlanmıştır [20].

$$
\begin{gathered}
w_{k h}(n)=0,5\left\{\frac{I_{0}\left(\alpha_{k h} \sqrt{1-\left(\frac{2 n}{N-1}\right)^{2}}\right)}{I_{0}\left(\alpha_{k h}\right)}+0,54-0,46 \cos 2 \pi\left(\frac{n}{N-1}+0,5\right)\right\} \\
|\mathrm{n}| \leq(\mathrm{N}-1) / 2 \text { için }
\end{gathered}
$$

Bu pencere şu şekilde elde edilmiştir. Denklem (5)'te tanımlanan Hamming penceresi, eklendiği pencere ile uyumluluk göstermesi açısından zamanda (N-1)/2 kadar ötelenmiş ve Denklem (3)'te tanımlanan Kaiser penceresi ile birleştirilmiştir. Şekil 1a'daki gibi birim genlik sağlaması için, fonksiyon, 0,5 ile ölçeklendirilmiștir. Önerilen pencere; Kaiser penceresinde olduğu gibi, pencere uzunluğu $(\mathrm{N})$ ve ayarlanabilir değişken $\left(\alpha_{\mathrm{kh}}\right)$ olarak tanımlanmış, iki bağımsız değişkene sahiptir. $\mathrm{Bu}$ parametrelerin, pencere spektrumu ve tasarlanacak süzgeç üzerindeki etkileri üçüncü bölümde anlatılmaktadır.

\subsection{Süzgec Spektral Parametreleri (Filter Spectral Parameters)}

$\mathrm{Bu}$ çalışmada, prototip özelliklerinden dolayı alçak geçiren süzgeçler üzerinde durulmuştur. Diğer tipteki süzgeçler, uygun dönüşüm yöntemleriyle, alçak geçiren süzgeçlerden kolaylıkla elde edilebilir. Dönüşüm sonucunda frekans bantlarının değişecek olmasina rağmen minimum durdurma-bandı zayıflatma oranları değişmeyeceğinden; alçak geçiren süzgeçler için elde edilen sonuçlar; diğer süzgeçler içinde aynı olacaktır. 
Şekil 2'de, bir süzgecin spektral parametreleri olan geçirme-band1 frekansı $\left(\mathrm{w}_{\mathrm{p}}\right)$, durdurma-band1 frekansı $\left(\mathrm{w}_{\mathrm{st}}\right)$, maksimum geçirme-bandı zayıflatması $\left(\mathrm{A}_{\mathrm{p}}\right)$ ve minimum durdurma-bandı zayıflatması $\left(\mathrm{A}_{\mathrm{s}}\right)$ gösterilmektedir. Bunlarla birlikte, kesme frekansı $\left(\mathrm{w}_{\mathrm{ct}}\right)$ ve geçiş bandı genişliği $(\Delta \mathrm{w})$ gibi diğer spektral parametreler, Denklem (7) ve (8) ile ifade edilmektedir.

$w_{c t}=\left(w_{s t}+w_{p}\right) / 2$

$\Delta w=w_{s t}-w_{p}$

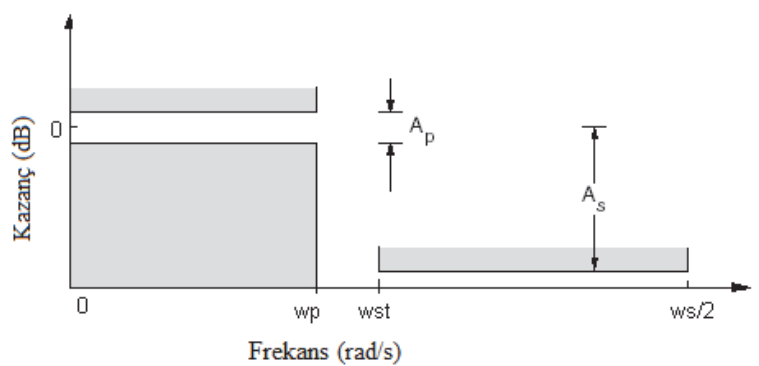

Şekil 2. Alçak geçiren bir süzgecin genlik spektrumu (Amplitude spectrum of a lowpass filter)

2.7. Pencereler Kullanarak Yinelemesiz Sayısal Süzgeç Tasarımı (Nonrecursive Digital Filter Design Using Windows)

Fourier seri metodu, yinelemesiz sayısal süzgeç tasarım metotlarından biridir. Bu metotta bir pencere kullanılmasının amacı; ideal süzgecin, sonsuz dürtü tepkisini kesmek ve düzleştirmektir. Pencere kullanarak elde edilen nedensel olmayan süzgecin dürtü tepkisi, Denklem (9)'dan bulunur [1].

$h_{n c}(n T)=w(n T) h_{i d}(n T)$

Burada, $h_{i d}(n T)$, gerçekleştirilemeyen ideal süzgecin sonsuz süreli dürtü tepkisidir. Alçak geçiren bir süzgeç için, bu dürtü tepkisi, Denklem (10)'dan bulunabilir [1].

$h_{i d}(n T)=\left\{\begin{array}{ccc}w_{c t} T / \pi & n=0 & i c ̧ i n \\ \sin _{c t} n T / n \pi & n \neq 0 & i c ̧ i n\end{array}\right.$

Hesaplanan nedensel olmayan dürtü tepkisinin, $h_{n c}(n T), \quad(N-1) / 2$ süresi kadar geciktirilmesiyle, nedensel bir süzgeç elde edilir. Bunun için, $0 \leq n \leq N-1$ aralığında Denklem (11) ile ifade edilen bağıntı kullanılır.

$h_{c}(n T)=h_{n c}[(n-(N-1) / 2) T]$

Pencere kullanarak tasarlanan süzgeçlerin; geçirmebandı ve durdurma-bandı bölgelerinde oluşan istenmeyen salınımlar birbirine eşittir. Dolayısıyla, benzeşim sonuçları bulurken, iki bölgeden sadece birindeki zayıflatma parametresini (Genelde $\mathrm{A}_{\mathrm{s}}$ ) hesaplamak yeterlidir.
Yinelemesiz sayısal süzgeçler; süzgeç uzunluklarının tek veya çift, dürtü tepki fonksiyonlarının simetrik veya asimetrik olmasına göre dört farklı şekilde tanımlanarak tasarlanabilir. Bu çalışmada; süzgeç uzunluğunun tek olması ve dürtü tepkisinin simetrik olması durumu göz önüne alınmıştır, çünkü sadece bu durumda tüm süzgeç yapıları gerçekleştirilebilirdir. Örneğin, formüller çift uzunluklu olarak tanımlandığında; bu durumda, yüksek geçiren ve bant durduran süzgeçler tasarlanamayıp, sadece alçak geçiren ve bant geçiren süzgeçler ile Hilbert dönüştürücüleri tasarlanabilecektir.

\section{BULGULAR VE TARTISMA (RESULTS AND DISCUSSION)}

Burada öncelikle önerilen pencerenin pencere spektral analizi yapılmış, daha sonra da yinelemesiz sayısal süzgeç tasarımındaki performansı karşılaştırmalı olarak incelenmiştir.

3.1. Kaiser-Hamming Penceresi için Pencere Spektral Analizi Benzeşim Sonuçları (Simulation Results of Window Spectral Analysis for Kaiser-Hamming Window)

$\mathrm{Bu}$ kısımda, önerilen pencerenin parametrelerinin; pencere spektrumu üzerindeki etkisi gözlemlenecek ve pencere spektral parametreleri ile aralarındaki ilişki bulunacaktır. Son olarak da, farklı pencere uzunlukları için Kaiser-Hamming, Kaiser ve Hamming pencereleri arasında karşılaştırmalar yapılacaktır.

3.1.1. Kaiser-Hamming penceresinin pencere spektral analizi (Window spectral analysis of KaiserHamming window)

Bağımsız parametreleri, $\mathrm{N}$ ve $\alpha_{\mathrm{kh}}$, olan KaiserHamming penceresinin; $N=51$ ve farklı $\alpha_{\mathrm{kh}}$ değerleri için, zaman bölgesindeki normalize genlik karakteristiği, Şekil 3a'da verilmiştir. $\alpha_{\mathrm{kh}}$ değerinin artmasıyla, genliğin, $\mathrm{n}=0$ merkezi noktasından itibaren uçlara doğru daha küçüldüğü ve uç genlik noktaların, sıfıra yaklaștığı görülmektedir. Denklem (2) kullanılarak, $N=51$ ve farklı $\alpha_{\mathrm{kh}}$ değerleri için önerilen pencerenin genlik spektrumları, Şekil 3b'de görüldüğü gibi bulunabilir. $\mathrm{N}=51$ ile birlikte, farklı pencere uzunlukları için pencere spektral parametre değerleri, ayrıca Tablo 1'de belirtilmiştir. Tablo 1'de, pencerenin yarım analob genişliği $\left(\mathrm{W}_{R}\right)$ ve tepecik oranı $(\mathrm{R})$ değerleri, sırasıyla $\mathrm{rad} / \mathrm{s}$ ve $\mathrm{dB}$ birimleriyle verilmiş olup; sabit bir pencere uzunluğunda $(\mathrm{N}), \alpha_{\mathrm{kh}}$ değeri arttığında, pencerenin $\mathrm{w}_{\mathrm{R}}$ değerinin arttığ 1 (daha kötüye gittiği) ve $\mathrm{R}$ değerinin azaldığ ${ }_{1}$ (daha iyiye gittiği) görülmektedir. Ayrıca, sabit bir $\alpha_{\mathrm{kh}}$ değerinde pencere uzunluğu arttığında, $w_{R}$ değerinin büyük bir oranda azaldığı ve $\mathrm{R}$ değerinin küçük bir oranda arttığı görülmektedir.

Önerilen pencerenin parametreleri olan $\mathrm{N}$ ve $\alpha_{\mathrm{kh}}$ ile pencere spektral parametreleri olan $w_{R}$ ve $R$ arasındaki ilişkileri bulmak; herhangi bir pencere spektral uygulama $[12,13,17,18]$ için gerekli pencerenin tespit edilmesi açısından önemlidir. 


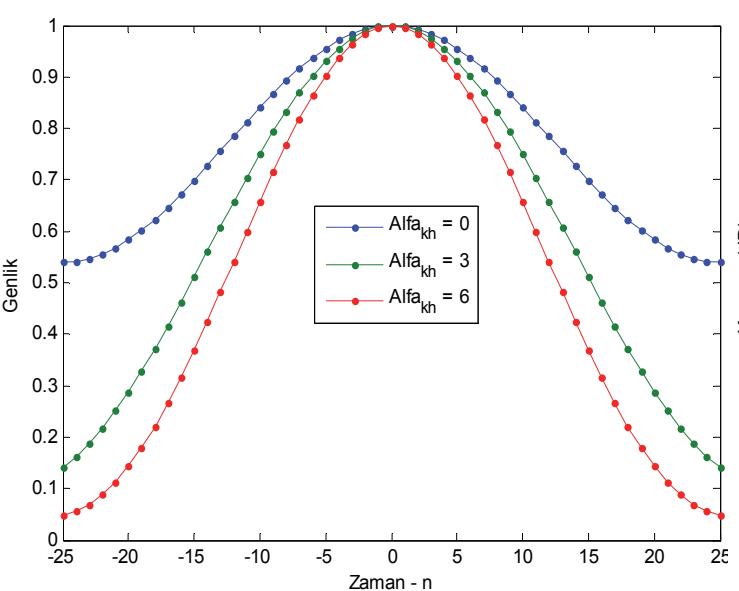

(a)

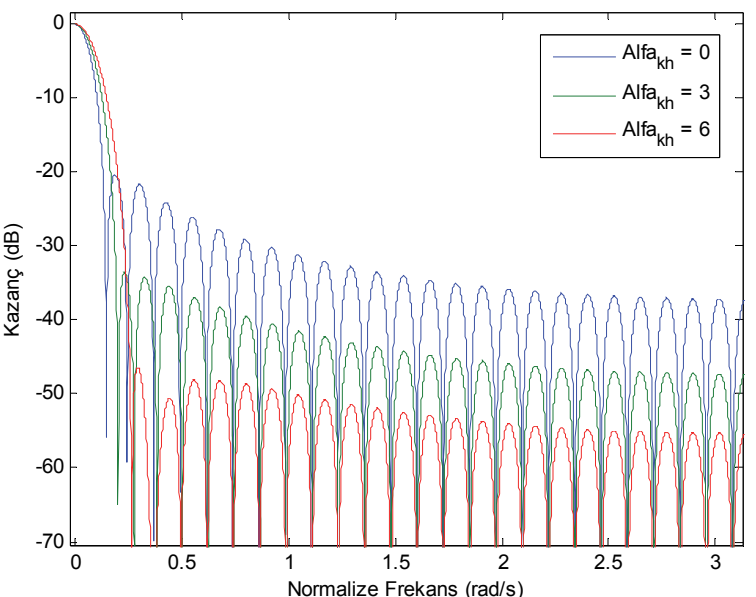

(b)

Şekil 3. (a) $N=51$ için önerilen pencerenin genlik karakteristiği ve (b) genlik spektrumu ((a) Amplitude characteristic of proposed window for $\mathrm{N}=51$ and (b) its amplitude spectrum)

Tablo 1. Önerilen pencerenin pencere spektral değerleri (Window spectral values of proposed window)

\begin{tabular}{|c|c|c|c|c|c|c|c|c}
\hline \multirow{2}{*}{$\boldsymbol{\alpha}_{\text {kh }}$} & \multicolumn{2}{|c|}{$\mathbf{N = 3 1}$} & \multicolumn{2}{c|}{$\mathbf{N}=\mathbf{5 1}$} & \multicolumn{2}{c|}{$\mathbf{N = 1 0 1}$} & \multicolumn{2}{c}{$\mathbf{N}=\mathbf{1 2 7}$} \\
\cline { 2 - 9 } & $\mathbf{w}_{\mathbf{R}}$ & $\mathbf{R}$ & $\mathbf{w}_{\mathbf{R}}$ & $\mathbf{R}$ & $\mathbf{W}_{\mathbf{R}}$ & $\mathbf{R}$ & $\mathbf{w}_{\mathbf{R}}$ & $\mathbf{R}$ \\
\hline 0 & 0,216 & $-20,47$ & 0,131 & $-20,32$ & 0,066 & $-20,20$ & 0,052 & $-20,18$ \\
\hline 3 & 0,322 & $-34,70$ & 0,191 & $-33,47$ & 0,095 & $-32,64$ & 0,076 & $-32,48$ \\
\hline 6 & 0,433 & $-47,00$ & 0,257 & $-46,33$ & 0,128 & $-45,66$ & 0,101 & $-45,51$ \\
\hline
\end{tabular}

Önerilen pencere için $\alpha_{\mathrm{kh}}$ ve R arasındaki ilişki, farklı pencere uzunluklarında, Şekil 4a'da verilmiştir. Kaiser penceresindeki genelde sabit $\alpha_{k}$ ve R ilişkisinden farklı olarak, $\mathrm{N}$ değerinin değişmesiyle bu ilişkinin önerilen pencere için daha çok değiştiği ve yaklaşık olarak $\alpha_{\mathrm{kh}}=6,5$ değerinden sonra $\mathrm{R}$ değerinin daha da azalmadığı görülmektedir. Farklı pencere uzunlukları için $\alpha_{\mathrm{kh}}-\mathrm{R}$ ilişkisi değiştiğinden, Kaiser penceresinde yapılabildiğinin aksine tüm $\mathrm{N}$ değerleri için geçerli bir $\alpha_{\mathrm{kh}}-\mathrm{R}$ pencere spektral denklemi, önerilen pencere için bulunamaz. Fakat her bir pencere uzunluk değeri için, Matlab'ta eğri uydurma metodu kullanarak istenen denklem türetilebilir.

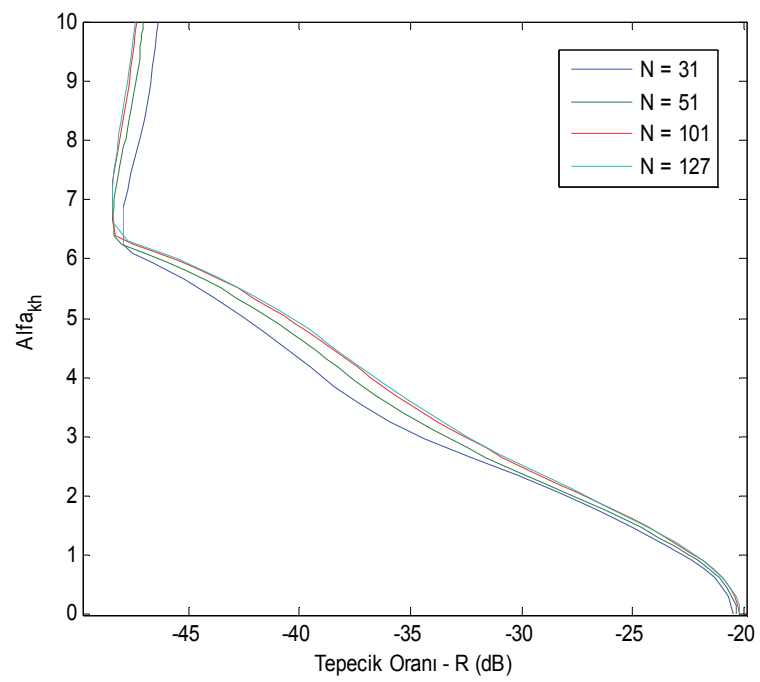

(a)
Önerilen pencere için, $\mathrm{R}$ ve normalize analob genişliği $\left(\mathrm{D}_{\mathrm{w}}=2 \mathrm{w}_{\mathrm{R}}(\mathrm{N}-1)\right)$ [19] arasındaki ilişki, farklı pencere uzunluklarında, Şekil 4b'de verilmiştir.

Kaiser penceresindeki sabit $\mathrm{R}$ ve $\mathrm{D}_{\mathrm{w}}$ ilişkisinden farklı olarak, $\mathrm{N}$ değerinin değişmesiyle bu ilişkinin önerilen pencere için değiştiği ve yaklaşı olarak $\mathrm{D}_{\mathrm{w}}=26,5$ $\mathrm{rad} / \mathrm{s}$ değerinden sonra tepecik oranının $\mathrm{R}=-48$ dB'den daha küçük bir noktaya gitmediği görülmektedir. Sonuç olarak, önerilen pencerenin, $\alpha_{\mathrm{kh}}$ $\leq 6,5$ ve $\mathrm{R} \geq-48 \mathrm{~dB}$ aralıklarında daha kullanışlı bir performans sergilediği görülmüştür.

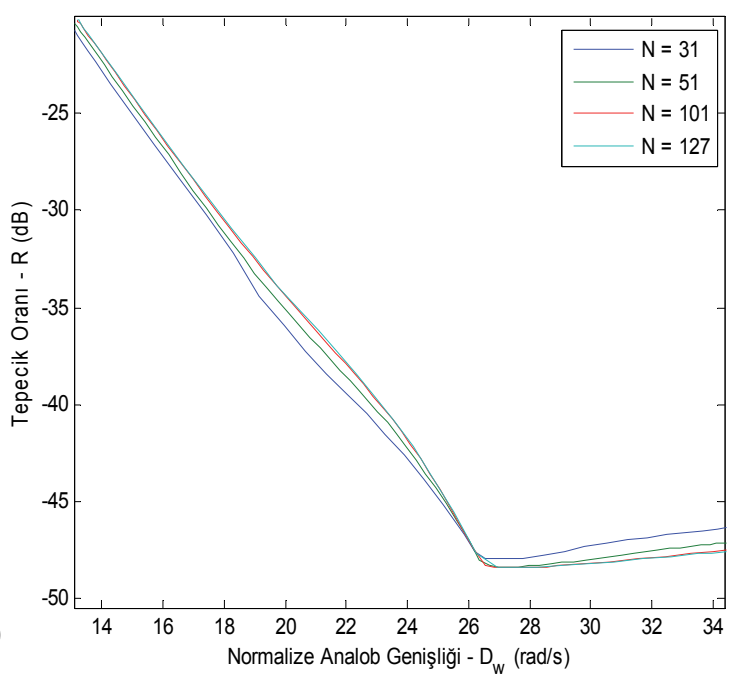

(b)

Şekil 4. (a) $N=31,51,101$ ve 127 için önerilen pencerede $\alpha_{k h}$ ve R ilişkisi ve (b) R ve $D_{w}$ ilişsisi ((a) $\alpha_{k h}$ and $R$ relationship of proposed window for $\mathrm{N}=31,51,101$, and 127 and (b) its $\mathrm{R}$ and $\mathrm{D}_{\mathrm{w}}$ relationship) 


\subsubsection{Kaiser ve Hamming pencereleriyle pencere spektral karşılaştırması (Window spectral comparison with Kaiser and Hamming windows)}

$\mathrm{Bu}$ kısımda, önerilen pencerenin, kendisini oluşturan Kaiser ve Hamming pencereleriyle pencere spektral karşılaştırmaları verilmektedir. Birinci karşılaştırmada, sabit bir pencere uzunluğu ve yarım analob genişliği için tepecik oranları kıyaslanırken; ikinci karşılaştırmada, farklı pencere uzunluklarında bu üç pencerenin $\mathrm{R}-\mathrm{D}_{\mathrm{w}}$ ilişkisi verilerek, istenen herhangi bir pencere spektral parametre üzerinden kiyaslama yapma olanağı sunulmuştur.

Birinci karşılaştırma olarak, Şekil 5'te, $\mathrm{N}=51$ pencere uzunluğu ve $\mathrm{w}_{\mathrm{R}}=0,244 \mathrm{rad} / \mathrm{s}$ yarım analob genişliği için pencerelerin genlik spektrumları verilmiştir. $\mathrm{N}=$ 51 ile birlikte, farklı pencere uzunlukları için pencere spektral değerleri, Tablo 2'de ayrıca verilmiştir. Burada, önerilen ve Kaiser pencereleri, sabit bir pencere uzunluğunda tek karakteristiğe sahip Hamming penceresi ile yarım analob genişlikleri eşit olacak şekilde ayarlanmış ve tepecik oranları karşılaştırılmıştır. Görüldüğü gibi önerilen pencere, Kaiser ve Hamming pencerelerinden daha iyi tepecik oranı sağlamaktadır.

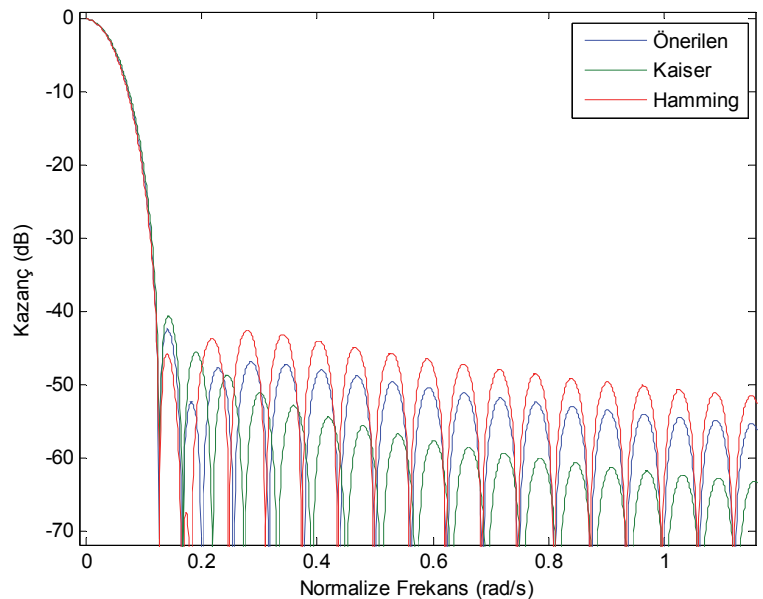

Şekil 5. $\mathrm{N}=51$ için önerilen, Kaiser ve Hamming pencerelerinin spektrumları (Spectrums of proposed, Kaiser, and Hamming windows for $\mathrm{N}=51$ )

İkinci karşılaştırma olarak, Kaiser-Hamming, Kaiser ve Hamming pencerelerinin farklı pencere uzunluklarında $\mathrm{R}$ ve $\mathrm{D}_{\mathrm{w}}$ karakteristikleri Şekil 6'da verilmiştir. Şekil 6'da görüldüğü gibi, önerilen pencere, $D_{w} \leq 28 \mathrm{rad} / \mathrm{s}$ (veya $R \geq-48 \mathrm{~dB}$ ) aralığındaki sabit bir analob genişliğinde, Kaiser penceresinden çok daha iyi tepecik oranı karakteristiği sağlamaktadır. Pencere uzunluğunun artmasıyla, bu farkın azaldı $\breve{g} 1$ da gözlemlenmektedir. Ayrıca, Kaiser penceresinin, $D_{w}>$ $28 \mathrm{rad} / \mathrm{s}$ (veya $\mathrm{R}<-48 \mathrm{~dB}$ ) aralığında, önerilen pencereden daha iyi bir performans sergilediği de görülmektedir.

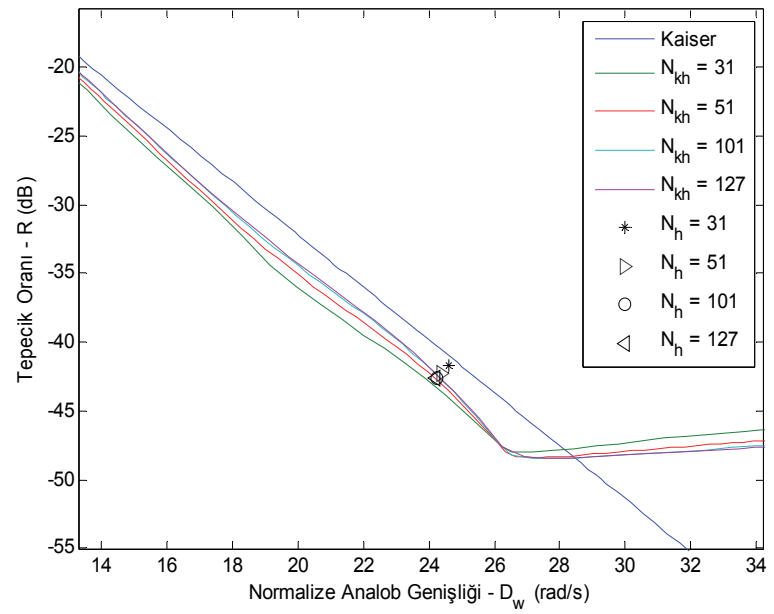

Şekil 6. $N=31,51,101$ ve 127 için önerilen pencerenin Kaiser ve Hamming pencereleriyle $\mathrm{R}$ ve $\mathrm{D}_{\mathrm{w}}$ cinsinden karşılaştırılması (Comparison of proposed window with Kaiser and Hamming windows in terms of $R$ and $D_{w}$ for $\mathrm{N}=31,51,101$, and 127)

\subsection{Kaiser-Hamming Penceresi için Yinelemesiz Süzgeç Tasarımı Benzeşim Sonuçları (Simulation Results of Nonrecursive Filter Design for Kaiser-Hamming} Window)

$\mathrm{Bu}$ kısımda öncelikle, önerilen pencerenin parametrelerinin ( $\mathrm{N}$ ve $\alpha_{\mathrm{kh}}$ ); sayısal süzgeç spektrumu üzerindeki etkisi gözlemlenecek ve sonra süzgeç spektral parametreleriyle $\left(\mathrm{A}_{\mathrm{s}}\right.$ ve $\left.\Delta \mathrm{w}\right)$ aralarındaki ilişki bulunacaktır. Ayrıca, Kaiser-Hamming, Kaiser, Cosh, Exponential ve Hamming pencereleriyle tasarlanan sayısal süzgeçler kıyaslanacak ve bir ses uygulaması örneği üzerinde süzgeçlerin performansları ölçülecektir.

3.2.1. Kaiser-Hamming penceresi ile yinelemesiz süzgeç tasarımı (Nonrecursive filter design with KaiserHamming window)

Şekil 7'de N = 51 ve farklı $\alpha_{\mathrm{kh}}$ değerleri için önerilen pencere kullanarak tasarlanan alçak geçiren süzgeçlerin genlik spektrumları görülmektedir. Ayrıca, $\mathrm{N}=51$ ile birlikte farklı süzgeç uzunlukları için süzgeç spektral değerleri Tablo 3 'te verilmiştir.

Tablo 2. Önerilen, Kaiser ve Hamming pencerelerinin pencere spektral değerleri (Window spectral values of proposed, Kaiser, and Hamming windows)

\begin{tabular}{|c|c|c|c|c|c|c|c|c|}
\hline \multirow{2}{*}{ Pencere } & \multicolumn{2}{|c|}{$\mathbf{N}=\mathbf{3 1}$} & \multicolumn{2}{c|}{$\mathbf{N = 5 1}$} & \multicolumn{2}{c|}{$\mathbf{N = 1 0 1}$} & \multicolumn{2}{c|}{$\mathbf{N}=127$} \\
\cline { 2 - 10 } & $\mathbf{w}_{\mathbf{R}}$ & $\mathbf{R}$ & $\mathbf{w}_{\mathbf{R}}$ & $\mathbf{R}$ & $\mathbf{w}_{\mathbf{R}}$ & $\mathbf{R}$ & $\mathbf{w}_{\mathbf{R}}$ & $\mathbf{R}$ \\
\hline Önerilen & 0,410 & $-44,01$ & 0,244 & $-43,17$ & 0,121 & $-42,40$ & 0,096 & $-42,25$ \\
\hline Kaiser & 0,410 & $-41,18$ & 0,244 & $-40,75$ & 0,121 & $-40,33$ & 0,096 & $-40,22$ \\
\hline Hamming & 0,410 & $-41,70$ & 0,244 & $-42,31$ & 0,121 & $-42,59$ & 0,096 & $-42,62$ \\
\hline
\end{tabular}




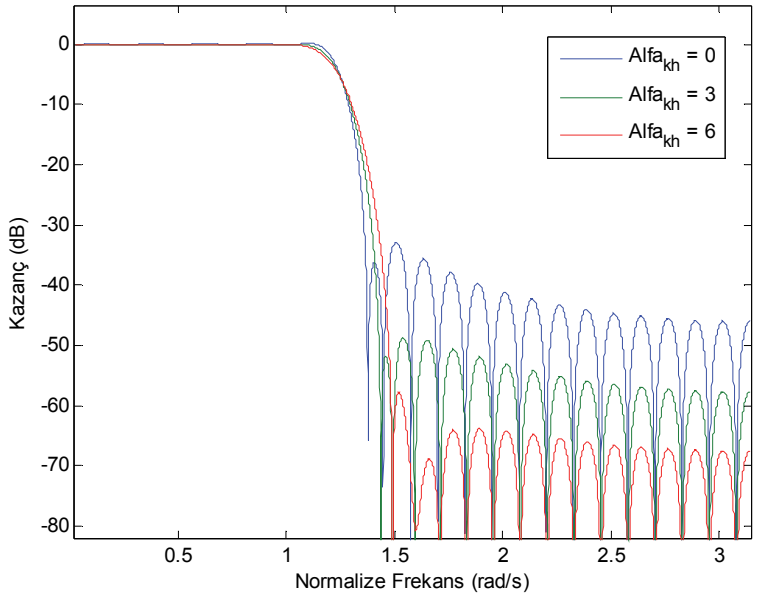

Şekil 7. $\mathrm{N}=51$ ile $\alpha_{\mathrm{kh}}=0,3$ ve 6 için önerilen pencereyle tasarlanan süzgeçlerin spektrumları (Spectrums of the filters designed by proposed window for $\mathrm{N}=51$ and $\alpha_{\mathrm{kh}}=0,3$, and 6 )

Tablo 3 'te süzgeçlerin $\Delta \mathrm{w}$ ve $\mathrm{A}_{\mathrm{s}}$ değerleri, sırasıyla $\mathrm{rad} / \mathrm{s}$ ve $\mathrm{dB}$ cinsinden verilmiş olup; sabit bir süzgeç uzunluğunda $(\mathrm{N}) \alpha_{\mathrm{kh}}$ değeri arttığında, süzgeçlerin $\Delta \mathrm{w}$ değerlerinin arttığı (daha kötüye gittiği) ve ayrıca $A_{s}$ değerlerinin arttığı (daha iyiye gittiği) görülmektedir. Ayrıca, sabit bir $\alpha_{\mathrm{kh}}$ değerinde süzgeç uzunluğu arttığında, $\Delta \mathrm{w}$ değerlerinin azaldığı (daha iyiye gittiği) ve $A_{s}$ değerlerinin çok küçük oranda değiştiği görülmektedir.
Kaiser-Hamming penceresi ile tasarlanmış süzgeçlerde, farklı süzgeç uzunlukları için $\alpha_{\mathrm{kh}}$ ve $\mathrm{A}_{\mathrm{s}}$ arasındaki ilişki, Şekil 8a'da verilmiştir. Kaiser penceresindeki sabit $\alpha_{k}-A_{s}$ ilişkisinden farklı olarak, süzgeç uzunluğunun değişmesiyle bu ilişkinin KaiserHamming penceresi için değiştiği görülmektedir. Bu yüzden tüm süzgeç uzunluk değerleri için geçerli olabilecek $\alpha_{\mathrm{kh}}$ ve $A_{\mathrm{s}}$ arasındaki ilişkiyi veren bir genel süzgeç tasarım denklemi bulunamaz, fakat her bir süzgeç uzunluğu için istenen denklem bulunabilir. Ayrıca, Şekil 8a'da, yaklaşık olarak $\alpha_{\mathrm{kh}}>7$ için $\mathrm{A}_{\mathrm{s}}$ 'nin daha da artmadığı (iyiye gitmediği) görülmektedir.

Kaiser-Hamming penceresiyle tasarlanan süzgeçlerde, farklı süzgeç uzunlukları için $A_{\mathrm{s}}$ ile normalize süzgeç geçiş bandı geniş̧liği $\left(\mathrm{D}_{\mathrm{f}}=\Delta \mathrm{w}(\mathrm{N}-1)\right)$ [4] arasındaki ilişki, Şekil 8b'de verilmiştir. $N$ değerinin değişmesiyle, bu ilişkinin de değiştiği gözlemlendiğinden; tüm $N$ değerlerini kapsayacak şekilde, $D_{f}$ ve $A_{s}$ arasında bir genel süzgeç tasarım denklemi bulunamaz. Ayrıca, yaklaşık olarak $A_{s}>63 \mathrm{~dB}$ için süzgecin $D_{f}$ değerinin artmasına rağmen $A_{s}$ değerinde artış olmadığından dolayı süzgeç karakteristiğinin daha iyiye gitmediği görülmektedir.

Sonuç olarak, benzeşim sonuçları; önerilen KaiserHamming penceresinin, $\alpha_{\mathrm{kh}} \leq 7$ ve $\mathrm{A}_{\mathrm{s}} \leq 63 \mathrm{~dB}$ aralıklarında daha kullanışlı bir süzgeçleme performansı sergilediğini göstermiştir.

Tablo 3. Önerilen pencereyle tasarlanan süzgeçlerin süzgeç spektral değerleri (Filter spectral values of the filters designed by proposed window)

\begin{tabular}{|c|c|c|c|c|c|c|c|c|}
\hline \multirow{2}{*}{$\boldsymbol{\alpha}_{\text {kh }}$} & \multicolumn{2}{|c|}{$\mathbf{N = 3 1}$} & \multicolumn{2}{c|}{$\mathbf{N = 5 1}$} & \multicolumn{2}{c|}{$\mathbf{N}=\mathbf{1 0 1}$} & \multicolumn{2}{c|}{$\mathbf{N}=\mathbf{1 2 7}$} \\
\cline { 2 - 9 } & $\mathbf{\Delta \mathbf { w }}$ & $\mathbf{A}_{\mathbf{s}}$ & $\mathbf{\Delta \mathbf { w }}$ & $\mathbf{A}_{\mathbf{s}}$ & $\Delta \mathbf{w}$ & $\mathbf{A}_{\mathbf{s}}$ & $\Delta \mathbf{w}$ & $\mathbf{A}_{\mathbf{s}}$ \\
\hline 0 & 0,348 & 32,89 & 0,210 & 32,87 & 0,105 & 32,79 & 0,083 & 32,24 \\
\hline 3 & 0,563 & 48,86 & 0,338 & 48,66 & 0,169 & 48,48 & 0,134 & 48,04 \\
\hline 6 & 0,755 & 57,60 & 0,454 & 57,73 & 0,227 & 57,92 & 0,181 & 58,79 \\
\hline
\end{tabular}

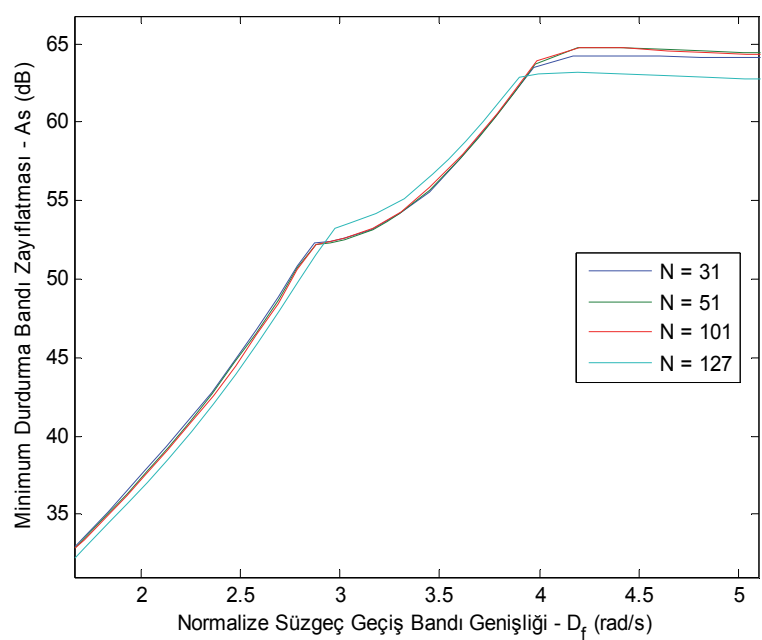

(a)

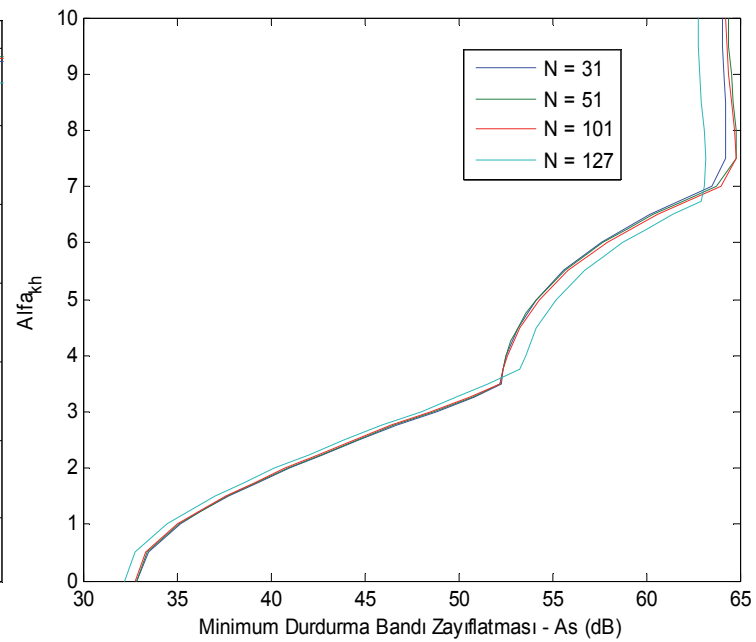

(b)

Şekil 8. (a) Önerilen pencereyle tasarlanan süzgeçlerde $\alpha_{k h}$ ve $A_{s}$ ilişkisi ve (b) $D_{f}$ ve $A_{s}$ ilişkisi ((a) $\alpha_{k h}$ and $A_{s}$ relationship of the filters designed by proposed window and (b) its $\mathrm{D}_{\mathrm{f}}$ and $\mathrm{A}_{\mathrm{s}}$ relationship) 
3.2.2. Kaiser-Hamming, Kaiser, Cosh, Exponential ve Hamming pencereleri ile süzgeç karşılaştırmaları (Filter comparisions with KaiserHamming, Kaiser, Cosh, Exponential, and Hamming windows)

Bu kısımda, önerilen Kaiser-Hamming penceresi ile tasarlanan süzgeçlerin; Kaiser, Cosh, Exponential ve Hamming pencereleriyle tasarlanan süzgeçlerle karşılaştırmaları verilmektedir.

Şekil 9a'da $\mathrm{N}=127$ için $\Delta \mathrm{w}=0,144 \mathrm{rad} / \mathrm{s}$ geçiş band 1 genişliğine ve $w_{c t}=0,4 \pi \mathrm{rad} / \mathrm{s}$ kesme frekansına sahip Kaiser-Hamming, Kaiser, Cosh ve Exponential pencereleriyle oluşturulan alçak geçiren süzgeçlerin, genlik spektrumları görülmektedir. $\mathrm{N}=127$ ile birlikte, farklı süzgeç uzunlukları ile ilgili süzgeç spektral değerleri, Tablo 4'te ayrıca verilmiştir. Sonuçlar, Kaiser-Hamming penceresi ile tasarlanan süzgeçlerin diğerlerine göre en iyi $A_{s}$ değerlerini sağladığını göstermektedir.

Şekil 9b'de ise Kaiser-Hamming, Kaiser ve Hamming pencereleriyle oluşturulan alçak geçiren süzgeçlerin, farklı süzgeç uzunluklarındaki $\mathrm{D}_{\mathrm{f}}-\mathrm{A}_{\mathrm{s}}$ karakteristikleri verilmiştir. Burada süzgeç uzunluğuna bağlı olarak
Kaiser-Hamming pencerenin, yaklaşık olarak $A_{\mathrm{s}}<54$ $\mathrm{dB}$ değerleri için Kaiser penceresinden daha iyi süzgeçleme performansı sağladığı görülmektedir.

\subsubsection{Süzgeç performans karşılaştırması için ses} uygulaması örneği (Audio application example for filter performance comparision)

$\mathrm{Bu}$ kısımda, önerilen pencereyle tasarlanan süzgeçlerin ses uygulamasındaki performansı, bir örnek üzerinden karşılaştırmalı olarak incelenmektedir. Gürültüsüz ses işareti olarak; Şekil 10'da gösterilen, $22.050 \mathrm{~Hz}$ örnekleme frekansına sahip, piyanonun La notalarından biri olan $\mathrm{A}_{0}$ sesi kullanılmıştır. $\mathrm{Bu}$ işarete, gürültü olarak, süzgeçlerin en zayıf süzgeçleme yaptığı $4.712 \mathrm{~Hz}$ frekansında, bir sinüzoidal işaret eklenmiştir. $\mathrm{Bu}$ gürültülü işaret, öncelikle Şekil 9a'da belirtilen önerilen KaiserHamming, Kaiser, Cosh ve Exponential pencereleri ile tasarlanmış $\mathrm{N}=127$ uzunluğundaki süzgeçlerden geçirilmiştir. Bu süzgeçler, verilen örnekleme frekansı için $0,4 \pi \times 22.050 / 2 \pi=4.410 \mathrm{~Hz}$ kesme frekansına ve $0,144 \times 22.050 / 2 \pi=505,35 \mathrm{~Hz}$ geçiş band1

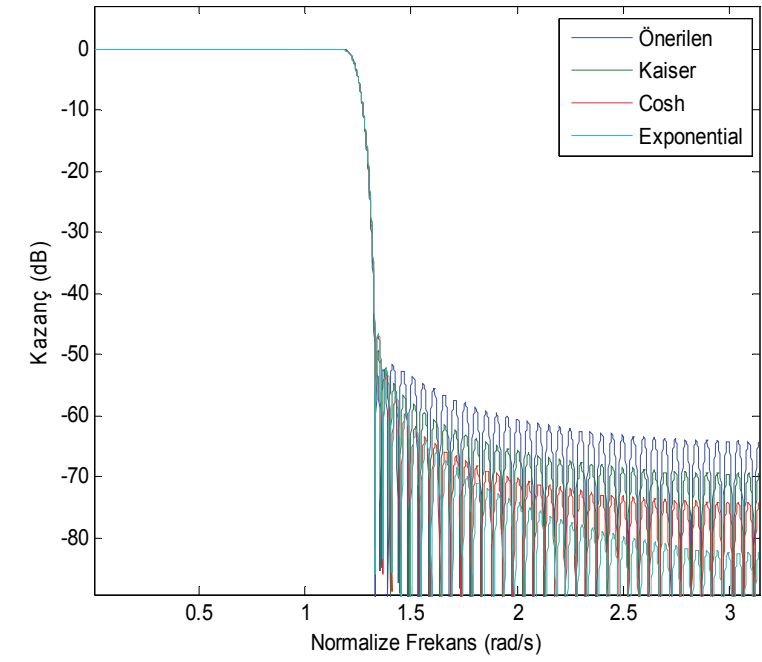

(a)

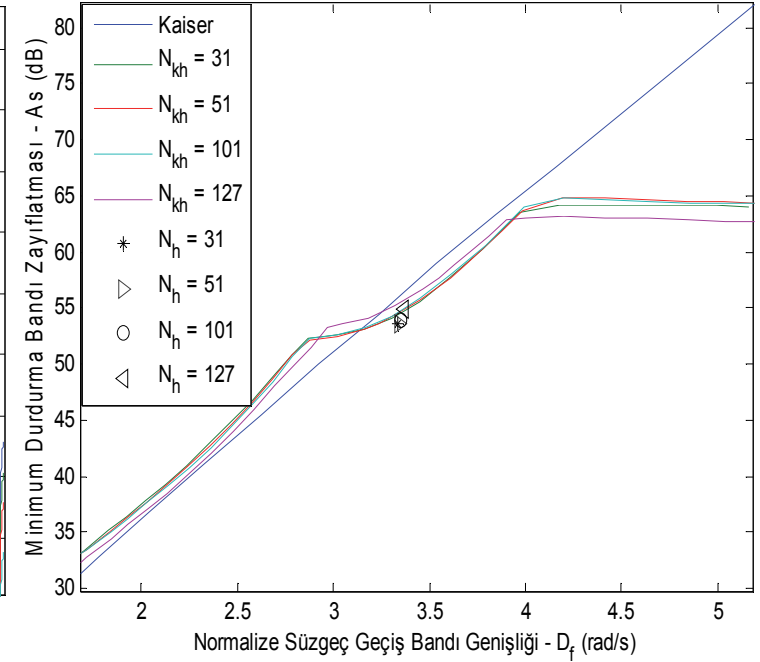

(b)

Şekil 9. (a) $\mathrm{N}=127$ için önerilen, Kaiser, Cosh ve Exponential pencereleriyle oluşturulan süzgeçler (b) Önerilen, Kaiser ve Hamming pencereleriyle tasarlanan süzgeçlerin farklı süzgeç uzunluklarında $D_{\mathrm{f}}-\mathrm{A}_{\mathrm{s}}$ karakteristikleri karşılaştırılması ( (a) Filters designed by proposed, Kaiser, Cosh, and Exponential windows for $\mathrm{N}=127$ (b) Comparison of $\mathrm{D}_{\mathrm{f}}-\mathrm{A}_{\mathrm{s}}$ characteristics for the filters designed by proposed, Kaiser, and Hamming Windows for different filter lengths)

Tablo 4. $w_{c t}=0,4 \pi \mathrm{rad} / \mathrm{s}$ için önerilen, Kaiser, Cosh ve Exponential pencereleriyle oluşturulan süzgeçlerin spektral değerleri (Spectral values of filters designed by proposed, Kaiser, Cosh, and Exponential windows for $w_{c t}=0,4 \pi \mathrm{rad} / \mathrm{s}$ )

\begin{tabular}{|c|c|c|c|c|c|c|c|c|}
\hline \multirow{2}{*}{ Pencere } & \multicolumn{2}{|c|}{$\mathbf{N = 3 1}$} & \multicolumn{2}{c|}{$\mathbf{N = 5 1}$} & \multicolumn{2}{c|}{$\mathbf{N = 1 0 1}$} & \multicolumn{2}{c|}{$\mathbf{N}=\mathbf{1 2 7}$} \\
\cline { 2 - 10 } & $\boldsymbol{\Delta \mathbf { w }}$ & $\mathbf{\mathbf { A } _ { \mathbf { s } }}$ & $\boldsymbol{\Delta \mathbf { w }}$ & $\mathbf{\mathbf { A } _ { \mathbf { s } }}$ & $\boldsymbol{\Delta \mathbf { w }}$ & $\mathbf{A}_{\mathbf{s}}$ & $\boldsymbol{\Delta \mathbf { w }}$ & $\mathbf{A}_{\mathbf{s}}$ \\
\hline Önerilen & 0,605 & 52,31 & 0,362 & 52,19 & 0,181 & 52,24 & 0,144 & 51,89 \\
\hline Kaiser & 0,605 & 49,12 & 0,362 & 48,99 & 0,181 & 48,98 & 0,144 & 49,36 \\
\hline Cosh & 0,605 & 46,71 & 0,362 & 46,61 & 0,181 & 46,59 & 0,144 & 46,84 \\
\hline Exponential & 0,605 & 46,43 & 0,362 & 46,31 & 0,181 & 46,31 & 0,144 & 46,43 \\
\hline
\end{tabular}


genişliğine sahiptirler. $N=127$ için gürültüsüz, gürültülü ve süzgeçlenmiş işaretlerin zaman karakteristikleri Şekil 10'da gösterilmiştir. Bu gürültülü ve süzgeçlenmiş işaretlerin spektrumu, Matlab Sptool arayüzü kullanılarak Şekil 11'deki gibi bulunmuştur. Şekil 11a'da, önerilen pencereyle tasarlanan alçak geçiren süzgecin, gürültülü işaretteki (Mavi) gürültüyü nasıl zayıflattığı görülmektedir. Şekil 11b'de ise, $N=127$ uzunluğundaki önerilen (Kırmızı), Kaiser (Yeşil), Cosh (Turkuaz) ve Exponential (Gri) pencereleri ile tasarlanan süzgeçler aynı ses örneği için ayrı ayrı kullanıldığında; önerilen pencere ile tasarlanan süzgecin gürültüyü daha iyi zayıflatıldığı görülmektedir.

Aynı ses uygulama örneği, $\mathrm{N}=127$ haricinde, $\mathrm{N}=31$, 51 ve 101 süzgeç uzunluklarında da denenmiş ve Şekil 11b'deki sonuçlarla birlikte elde edilen süzgeçlenmiş işaretteki gürültünün spektral genlik değerleri Tablo 5'te $\mathrm{dB}$ cinsinden ayrica verilmiştir. Görüldüğü üzere, önerilen pencere ile tasarlanan süzgeçler, -33,13 dB büyüklüğündeki gürültüyü, diğerlerine göre daha iyi süzgeçleyip daha küçük bir değere indirgemektedir. Süzgeç uzunluğu arttığında, gürültünün daha da zayıflatıldığı aynı tablodan görülmektedir.
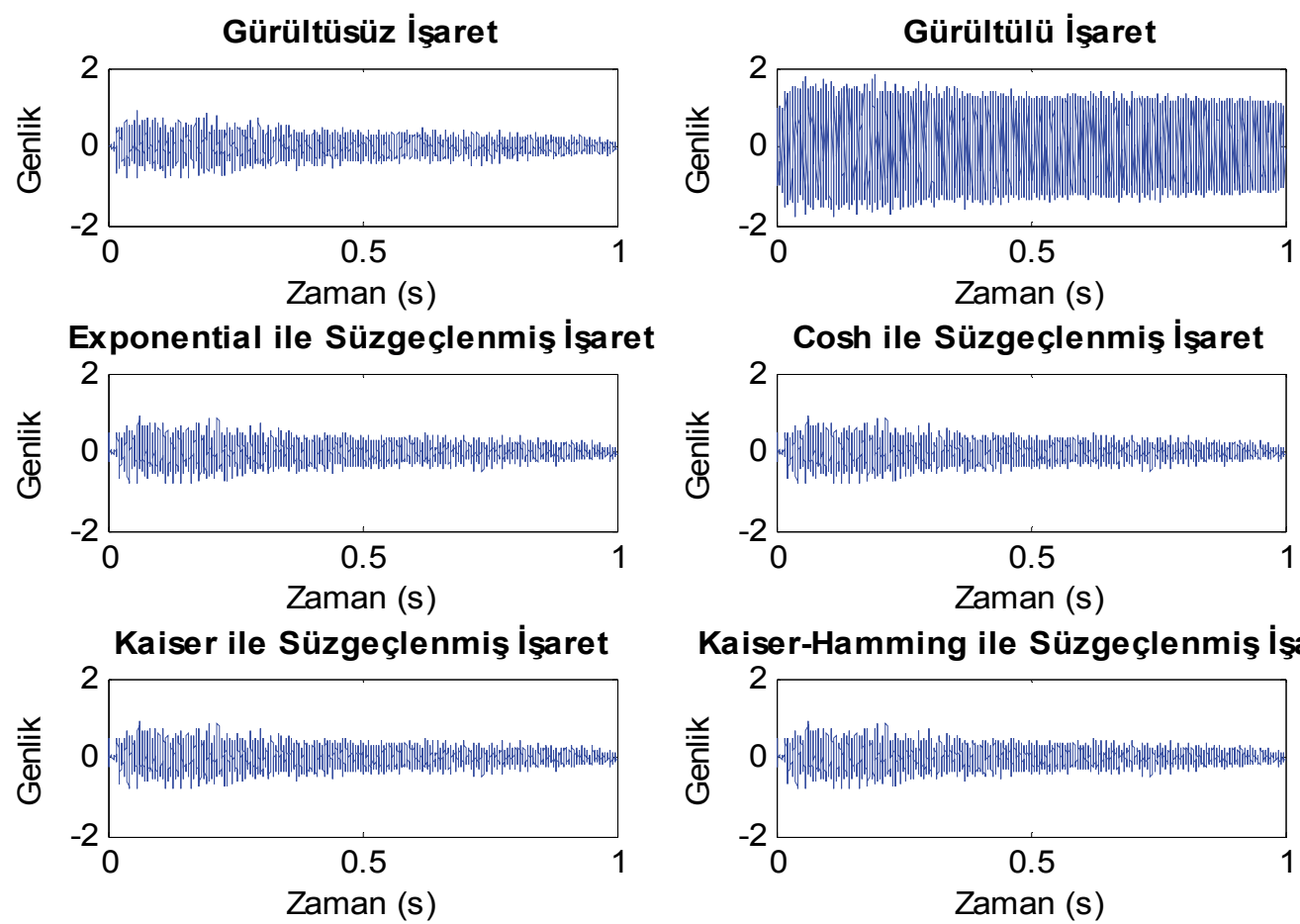

Şekil 10. Ses örneğinde kullanılan gürültüsüz, gürültülü ve $N=127$ için süzgeçlenmiş işaretler (Clear, noisy, and filtered signals used in audio example for $\mathrm{N}=127$ )

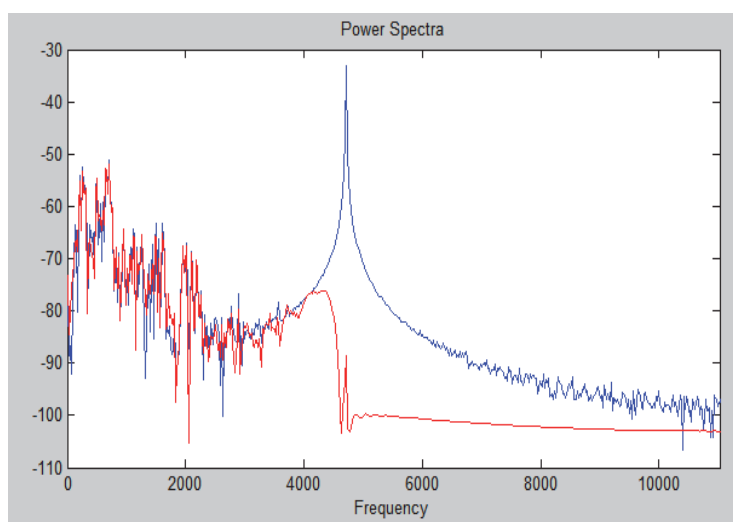

(a)

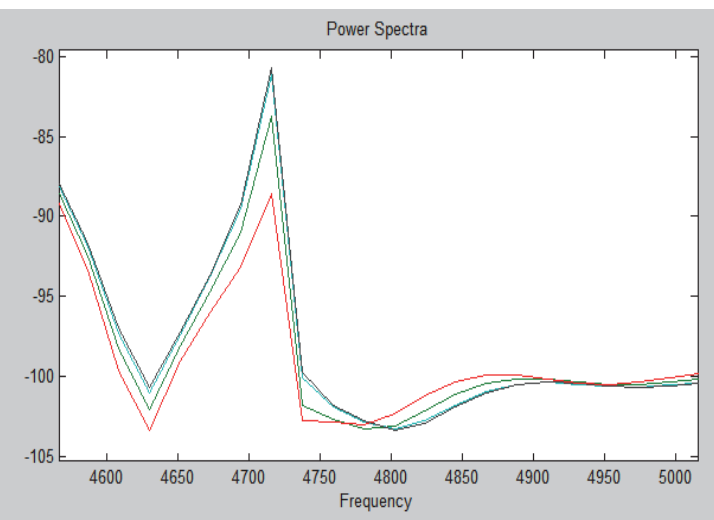

(b)

Şekil 11. (a) Gürültülü işaretin (Mavi) ve önerilen (Kırmızı) pencereyle süzgeçlenmiş işaretin spektrumları (b) $\mathrm{N}=127$ için önerilen (Kırmızı), Kaiser (Yeşil), Cosh (Cyan) ve Exponential (Gri) pencereleriyle süzgeçlenmiş işaretlerin spektrumları ((a) Spectrums of the noisy signal (blue) and the signal filtered by proposed window (red) (b) Spectrums of the signals filtered by proposed (Red), Kaiser (Green), Cosh (Cyan), and Exponential (Gray) windows for N = 127) 
Tablo 5. Farklı süzgeç uzunlukları için süzgeçlerden geçen işaretteki gürültünün $\mathrm{dB}$ olarak spektral genlik değerleri (Süzgeçlenmemiş gürültü değeri: $-33,13 \mathrm{~dB}$ ) (Spectral amplitude values of the noise in $\mathrm{dB}$ in filtered signal by the filters for different filter lengths (Unfiltered noise value: $-33,13 \mathrm{~dB}$ ))

\begin{tabular}{|c|c|c|c|c|}
\hline Pencere & $\mathbf{N}=\mathbf{3 1}$ & $\mathbf{N}=\mathbf{5 1}$ & $\mathbf{N}=\mathbf{1 0 1}$ & $\mathbf{N}=\mathbf{1 2 7}$ \\
\hline Önerilen & $-44,64$ & $-49,99$ & $-78,08$ & $-88,57$ \\
\hline Kaiser & $-44,52$ & $-49,67$ & $-76,70$ & $-83,78$ \\
\hline Cosh & $-44,41$ & $-49,41$ & $-75,66$ & $-81,11$ \\
\hline Exponential & $-44,38$ & $-49,37$ & $-75,48$ & $-80,71$ \\
\hline
\end{tabular}

\section{SONUÇLAR (CONCLUSIONS)}

$\mathrm{Bu}$ çalışmada, süzgeç uygulamalarında Kaiser penceresinden daha iyi sonuçlar elde etmek amacıyla yeni bir pencere önerilmiştir. Kaiser ve Hamming pencerelerinden türetildiği için; önerilen pencere, bu çalışmada Kaiser-Hamming olarak adlandırılmıştır. Süzgeç uygulamalarında kullanmadan önce, pencere kalitesinin belirlenmesi amacıyla; önerilen pencerenin farklı pencere uzunluklarında tepecik oranı (R) ve analob genişliği $\left(\mathrm{w}_{\mathrm{R}}\right)$ parametreleri cinsinden pencere spektral analizi yapılmıştır. Pencere spektral parametreleri olarak adlandırılan tepecik oranı ve analob genişliği; süzgeç karakteristiğindeki iki önemli parametre olan ve süzgeç spektral parametreleri olarak bilinen, minimum-durdurma bandı zayıflatması $\left(A_{s}\right)$ ve geçiş bandı genişliği $(\Delta w)$ ile doğrudan ilişkidir. Ayrıca, pencere ve süzgeç uzunlukları da birbiriyle bağlantılıdır.

Pencere spektral benzeşim sonuçları, önerilen pencerenin $\alpha_{\mathrm{kh}} \leq 6,5$ için kullanışlı olduğunu ve $\mathrm{R} \geq$ $48 \mathrm{~dB}$ değerleri için Kaiser penceresinden daha iyi pencere spektral karakteristiği sağladığını göstermiştir. Süzgeç benzeşim sonuçları ise, önerilen pencerenin $\alpha_{\mathrm{kh}} \leq 7$ için süzgeç uygulamalarında kullanışlı olduğunu ve süzgeç uzunluğuna bağlı olarak yaklaşık $A_{s}<54 \mathrm{~dB}$ değerleri için Kaiser penceresinden daha iyi süzgeç spektral karakteristiği sağladığını göstermiştir. Sonuç olarak, Şekil 6 ve Şekil 9b'de görüldüğü üzere; sırasıyla, nispeten daha büyük tepecik oranının veya daha küçük minimum durdurma-bandı zayıflatmasının gerektiği biyomedikal ve haberleşme alanlarındaki pencere ve süzgeç uygulamalarında, önerilen pencerenin Kaiser penceresine tercih edilebileceği sonucuna varılmıştır. Ayrıca, farklı süzgeç uzunlukları için, KaiserHamming penceresiyle tasarlanan alçak geçiren süzgeçlerin; diğer iki parametreli pencerelerden olan Kaiser, Cosh ve Exponential pencereleriyle tasarlanan süzgeçlerden daha iyi süzgeç spektral karakteristiği sağladıkları görülmüştür. Bununla birlikte, KaiserHamming penceresi ile tasarlanan süzgeçlerin süzgeçleme performansı bir ses örneği üzerinden uygulamalı olarak test edilmiş ve diğer pencerelerle tasarlanan süzgeçlere göre ses işaretindeki gürültüyü daha iyi zayıflattığı bulunmuştur.

\section{KAYNAKLAR (REFERENCES)}

1. Antoniou, A., Digital Signal Processing: Signal, Systems, and Filters, McGraw-Hill, A.B.D., 2005.

2. Kaiser, J.F., "Nonrecursive Digital Filter Design Using $\mathrm{I}_{0}$-sinh Window Function", Proceedings of IEEE Int Symp Circuits and Systems (ISCAS'74), San Francisco, Calif, USA, 20-23, 1974.

3. Saramaki, T., "A Class of Window Functions with Nearly Minimum Sidelobe Energy for Designing FIR Filters", In proc. IEEE Int. Symp. Circuits and systems (ISCAS'89), Portland, Ore, USA, Cilt 1, 359-362, 1989.

4. Bergen, S.W.A. ve Antoniou, A., "Design of Nonrecursive Digital Filters Using the Ultraspherical Window Function", Eurasip J Adv Sig Pr, Cilt 2005, No 12, 1910-1922, 2005.

5. Avci, K. ve Nacaroğlu, A., "Cosh Window Family and its Application to FIR Filter Design", AEU-Int J Electron C, Cilt 63, No 11, 907-916, 2009.

6. Avci, K. ve Nacaroğlu, A., "Design of Nonrecursive Digital Filters Using the Exponential Window", International Journal of Advanced Electrical \& Electronics Engineering, Cilt 2, No 2, 308-316, 2013.

7. Avci, K. ve Nacaroğlu, A., "Nonrecursive Digital Filter Design Using a Three-parameter Window Based on Cosine Hyperbolic Function", Proc. of 10th International Conference Digital Signal Processing and its Applications (DSPA'2008). Moskova, Rusya, 121-124, 25-29 Mart 2008.

8. Avci, K. ve Nacaroğlu, A., "High Quality Low Order Nonrecursive Digital Filter Design Using Modified Kaiser Window", Proc. of 6th Symposium on Communication Systems, Networks and Digital Signal Processing (CSNDSP'08), Graz, Avusturya, 239-242, 23-25 Temmuz 2008.

9. Mottaghi-Kashtiban, M. ve Shayesteh, M.G., "New Efficient Window Function, Replacement for the Hamming Window", IET Signal Processing, Cilt 5, No 5, 499-505, 2011.

10. Pachauri, R., Saxena, R. ve Sharma, S.N., "Studies on Z-Window Based FIR Filters", ISRN Signal Processing, 2013. doi:10.1155/2013/148646. 
11. Saramaki, T., "Finite Impulse Response Filter Design", Handbook for Digital Signal Processing, Editör: Mitra, K. ve Kaiser, J.F., Wiley \& Sons, NY, A.B.D., 1993.

12. Kaiser, J.F. ve Schafer, R.W., "On the Use of the $\mathrm{I}_{\mathrm{O}}$-sinh Window for Spectrum Analysis", IEEE T Acoust Speech, Cilt 1980, No 28, 105-107, 1980.

13. Seydnejad, S.R. ve Kitney, R.I., "Real-Time Heart Rate Variability Extraction Using the Kaiser Window", IEEE T Bio-Med Eng, Cilt 44, No 10, 990-1005, 1997.

14. Kaya, T. ve İnce M.C., "Yapay Sinir Ağları Yardimiyla Modellenen Pencere Fonksiyonu Kullanarak FIR Filtre Tasarımı", Journal of the Faculty of Engineering and Architecture of Gazi University, Cilt 27, No 3, 599-606, 2012.

15. Ashutosh, D., Alok, J. ve Pramod, C.S., "Design and Performance Analysis of Adjustable Window Functions based Cosine Modulated Filter Banks", Digit Signal Process, Cilt 23, No 1, 412-417, 2013.

16. Ramkumar, S., Alok J. ve Rajiv, S., "An Optimized Design of Nonuniform Filter Bank
Using Variable-Combinational Window Function", AEU-Int J Electron C, Cilt 67, No 7, 595-601, 2013.

17. Aljahdali, S., Nofal, M. ve Albagory, "A modified Array Processing Technique Based on Kaiser Window for Concentric Circular Arrays", International Conference on Multimedia Computing and Systems (ICMCS), Tangier, Fas, 458-461, 10-12 May1s 2012.

18. Sumamo, L., "Handwritten Word Segmentation using Kaiser Window", International Conference on Quality in Research (QIR), Yogyakarta, Endonezya, 73-78, 25-28 Haziran 2013.

19. Bergen S.W.A. ve Antoniou A., "Design of Ultraspherical Window Functions with Prescribed Spectral Characteristics", Eurasip J Adv Sig Pr, Cilt 2004, No 13, 2053-2065, 2004.

20. Avci, K., "Yinelemesiz Sayısal Süzgeç Tasarımı İçin Kaiser-Hamming Penceresinin Performans Analizi”, 21. Sinyal İşleme ve İletişim Uygulamaları Kurultayı (SİU 2013), Girne, KKTC, 1-4, 24-26 Nisan 2013. 
